\title{
Inter-observer agreement for spectral- and time-domain optical coherence tomography image grading: a prospective study
}

\author{
Pascal B. Knecht • Helena Kordic • \\ Malaika Kurz-Levin • Veit Sturm • \\ Marcel N. Menke
}

Received: 12 June 2012/ Accepted: 10 September 2012/Published online: 22 September 2012

(C) Springer Science+Business Media B.V. 2012

\begin{abstract}
The purpose of this study was to compare inter-observer agreement of Stratus ${ }^{\mathrm{TM}}$ OCT versus Spectralis ${ }^{\mathrm{TM}}$ OCT image grading in patients with neovascular age-related macular degeneration (AMD). Thirty eyes with neovascular AMD were examined with Stratus ${ }^{\mathrm{TM}}$ OCT and Spectralis ${ }^{\mathrm{TM}}$ OCT. Four different scan protocols were used for imaging. Three observers graded the images for the presence of various pathologies. Inter-observer agreement between OCT models was assessed by calculating intra-class correlation coefficients (ICC). In Stratus ${ }^{\text {TM }}$ OCT highest interobserver agreement was found for subretinal fluid (ICC: 0.79), and in Spectralis ${ }^{\mathrm{TM}}$ OCT for intraretinal cysts (IRC) (ICC: 0.93). Spectralis ${ }^{\mathrm{TM}}$ OCT showed superior interobserver agreement for IRC and epiretinal membranes (ERM) (ICC Stratus $^{\mathrm{TM}}$ : for IRC 0.61; for

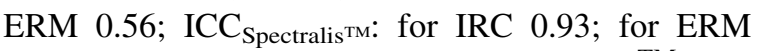
0.84). Increased image resolution of Spectralis ${ }^{\mathrm{TM}} \mathrm{OCT}$ did improve the inter-observer agreement for grading intraretinal cysts and epiretinal membranes but not for other retinal changes.
\end{abstract}

P. B. Knecht · H. Kordic · M. Kurz-Levin ·

V. Sturm · M. N. Menke

Department of Ophthalmology, University Hospital

Zurich, Zurich, Switzerland

M. N. Menke ( $\square)$

Department of Ophthalmology, University Hospital Bern, 3010 Bern, Switzerland

e-mail: marcel.menke@gmail.com
Keywords Age-related macular degeneration . Image grading - Optical coherence tomography · Reproducibility $\cdot$ Retina

\section{Introduction}

Optical coherence tomography (OCT) was introduced in 1991 as a non-invasive, cross sectional imaging technique [1]. In 1995 Time-Domain OCT (TD-OCT) was used first for imaging macular diseases with many studies published about imaging in age-related macular degeneration (AMD) [2-15]. In neovascular AMD, retinal structure can be disturbed by choroidal neovascularisation $(\mathrm{CNV})$ which is frequently associated with intraretinal cysts (IRC), subretinal fluid accumulation (SRF), pigment epithelium detachments (PED), and epiretinal membranes (ERM). In addition, one can frequently observe subretinal hyper-reflective material (SHM) in OCT images that might correspond to subretinal scar tissue, haemorrhages, fibrin formation and subretinal deposition or choroidal neovascularisations.

Recently, different treatment modalities for neovascular AMD have been introduced [11, 12, 16-19]. Conventional TD-OCT plays an important role in following patients with neovascular AMD during therapy with intravitreal anti-VEGF agents such as ranibizumab or bevacizumab [16]. OCT imaging was part of main outcome measures in various clinical trials. 
This led to the creation of OCT reading centers where independent observers review OCT scans for defined pathologies and retinal thickness measurements. Data regarding OCT retinal thickness measurement reproducibility has been published previously [20-27].

Recently, improvements in OCT technology have been introduced [28, 29]. Spectral-Domain OCT (SD-OCT) provides increased resolution and scanning speed by recording the interferometric information using a Fourier-domain-spectrometric method. Axial resolution is up to five microns and imaging speed is up to 100 times faster than in conventional TD-OCT $[30,31]$. In addition to radial line scans (RLS), SD-OCT can perform high-density volume scans (VS). These volume scans provide considerably more data compared to the six radial line scans of conventional TD-OCT and allow calculation of a threedimensional map of the macula with less need for interpolation within the scanning area. Some SD-OCT devices offer averaging of multiple scan images for noise reduction and in addition a real time eye tracking for improved reproducibility of measurements. SDOCT has been used previously to demonstrate its ability to visualize macular pathologies in patients with AMD [32-36].

One can hypothesize that higher scan resolution and greater scan coverage, i.e. higher number of B-scans, might lead to increased identification of retinal lesions in AMD and a higher interpretation agreement between different clinicians (inter-observer agreement).

Our goal was to compare the result of TD-OCT with SD-OCT in terms of grading-agreements between three independent observers. Two scan types in each OCT device were used.

\section{Methods}

Thirty eyes of 28 patients with previously diagnosed neovascular AMD were included in this prospective, comparative, observational study. Exclusion criteria were patients with severe media opacity, patients unable to undergo OCT examination, and patients with vast central subretinal hemorrhages that make OCT image interpretation impossible. OCT images had to be of good quality which was considered if all single line scans within a scan type showed a good signal with detailed retinal structure, no blinking artifacts, and no problems with the retinal thickness measurement algorithm. The initial diagnosis of exudative AMD was established by fundus examination and fluorescein angiography. All study patients were recruited from the retina unit of the Department of Ophthalmology, University Hospital Zurich, Switzerland. All patients had previous anti-VEGF treatments with either bevacizumab or ranibizumab for their $\mathrm{CNV}$ and were planned for regular follow-up examinations. Study patients gave written informed consent to participate in this study, which was approved by the local ethics committee.

For OCT, Stratus ${ }^{\text {TM }}$ OCT (Zeiss Meditec, Dublin, CA, USA, Softwareversion 4.0.7) was used for Fast Macular scan (FMS) and Cross Hair scan (CHS). FMS consists of 6 intersecting line scans in a spoke wheellike pattern. Each line is $6 \mathrm{~mm}$ long and includes 128 A-scans. The CHS consists of two intersecting line scans of $6 \mathrm{~mm}$ length in a cross pattern. Each line scan includes 512 A-scans. Both scan protocols were chosen, because they belong to the most common used protocols in clinical routine and in ongoing clinical trials. Spectralis ${ }^{\mathrm{TM}}$ OCT (Heidelberg Engineering, Heidelberg, Germany, Softwareversion 5.3) was used to perform high-resolution volume scans (VS), and radial line scans (RLS). For the VS, a raster scan pattern consisting of 25 line scans was chosen for macular scanning in an area of $30 \times 20^{\circ}$. Each line scan was averaged 25 -times by the Spectralis ${ }^{\mathrm{TM}}$ OCT ART function. The Spectralis ${ }^{\mathrm{TM}}$ OCT is capable of performing more line scans per raster scan for even greater retinal coverage. However, since patients with AMD are rather old and visual acuity and fixation stability is relatively poor, scan numbers were reduced to 25 line scans in order to speed up the scanning process and to allow measurements in less than $3 \mathrm{~min}$. The RLS consists of 6 intersecting line scans similar to the FMS of Stratus ${ }^{\mathrm{TM}}$ OCT with 512 A-scan per line and a scan length of $20^{\circ}$. Figure 1 shows examples of all 4 OCT scan types.

Three observers (PBK, HK, MNM) reviewed the OCT scans of all study eyes independently. All observers were specialist for treating exudative AMD and experienced OCT user, but not specifically trained grader from an OCT reading center. All 120 scans (30 eyes $\times 4$ scan types) were presented in random order. Since the 4 scan types consisted of 6 (FMS), 2 (CHS), 6 (RLS), and 25 (VS) single line scans, a total of 1,170 single line scans were reviewed. Each observer was masked to the patient data and to the decision of the 
Fig. 1 Four different OCT scan types used in a left eye with neovascular agerelated macular degeneration. On the left, different scan patterns are projected on either infrared fundus images (Stratus ${ }^{\mathrm{TM}}$ OCT) or scanning laser ophthalmoscope fundus images (Spectralis ${ }^{\mathrm{TM}}$ OCT). All presented B-scan images on the right were performed in horizontal direction and focused on the fovea. Top fast macular scan pattern (Stratus ${ }^{\mathrm{TM}}$ OCT). Second from top Cross hair scan pattern (Stratus ${ }^{\mathrm{TM}}$ OCT). Third from top: Volume scan pattern (Spectralis ${ }^{\mathrm{TM}}$ OCT). Bottom Radial line scan pattern (Spectralis ${ }^{\mathrm{TM}}$ OCT). In all B-scan images one can appreciate two retinal pigment epithelium detachments and subretinal fluid accumulation

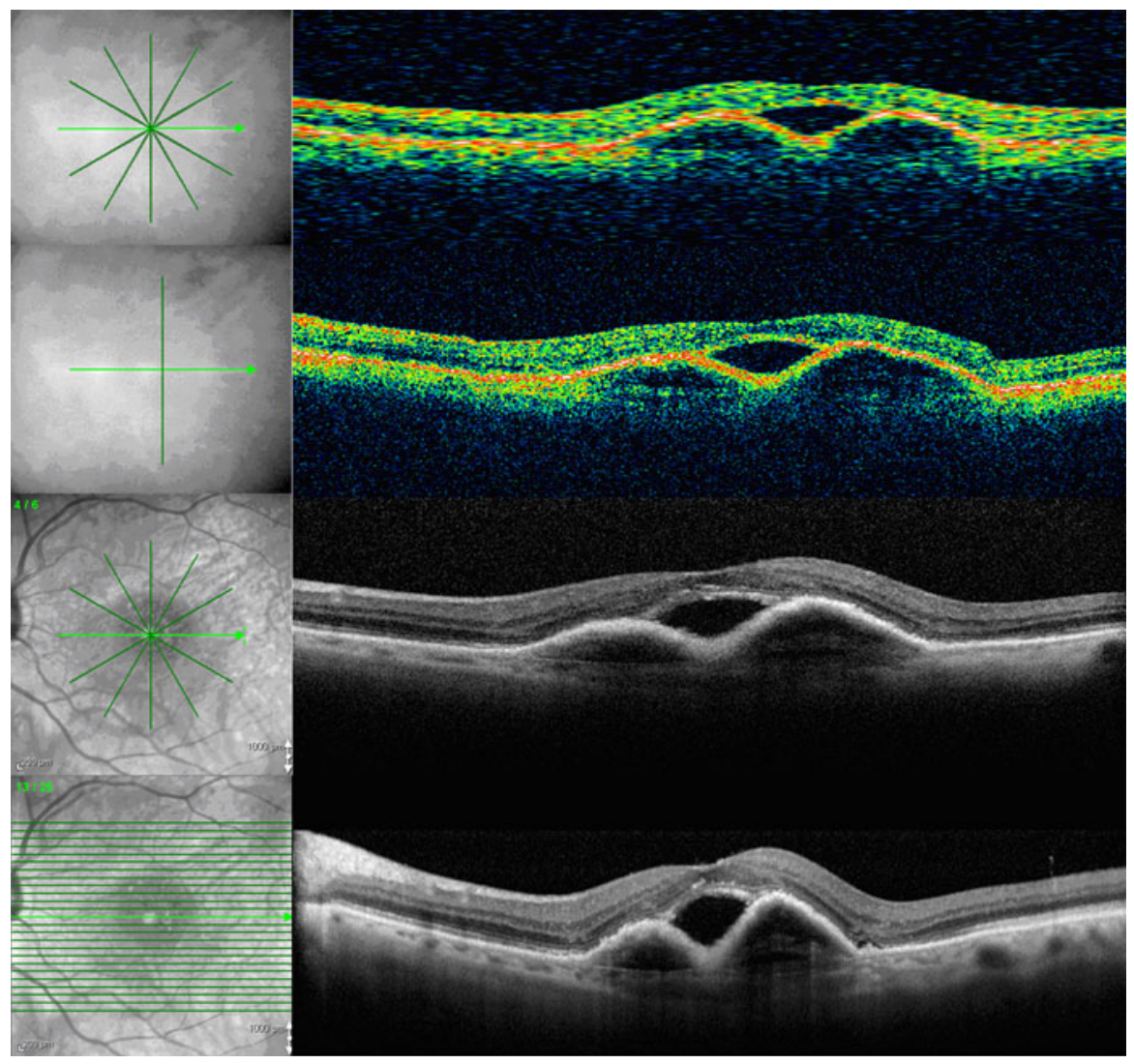

treating physician regarding re-treatment with intravitreal anti-VEGF drugs. Images were presented on a high resolution monitor.

Observers were asked to review each line scan within the scan protocol (FMS, CHS, VS, and RLS) and to give a summarized grading for each scan and eye for the absence $(=0)$ or presence $(=1)$ of IRC, SRF, PED, ERM, and SHM.

IRC were defined as the any noticeable presence of hypo-reflective, round or oval-shaped spaces within the neurosensory retina. SRF was defined as a hyporeflective space between the neurosensory retina and the retinal pigment epithelium. PED was defined as any elevation (not just localized thickening of the retinal pigment epithelium such as in Drusen) of the retinal pigment epithelium layer with consecutive elevation of the neurosensory retina. ERM was defined as a highly-reflective thin layer on top of the inner limiting membrane with or without retinal wrinkling. SHM was defined as a highly-reflective signal underneath the retinal pigment epithelium with an irregular shape, that cannot be classified as PED. SHM might be due to scar tissue, blood or neovascular material.

Intraclass correlation coefficients (ICC) were separately calculated to assess inter-observer agreement for grading morphologic pathologies within Stratus ${ }^{\mathrm{TM}}$ OCT (ICC Stratus $^{\mathrm{TM}}$; data of FMS and CHS gradings), and within Spectralis ${ }^{\mathrm{TM}}$ OCT $\left(\mathrm{ICC}_{\text {Spectralis }}{ }^{\mathrm{TM}}\right.$; data of VS and RLS gradings). Calculating ICC is a statistical procedure to determine the reproducibility (in this case inter-observer agreement) of a measurement of a variable. This correlation is based on variance components analysis and measures the homogeneity within groups relative to the total variation. The ICC is large when there is little variation within the groups compared to variation among group means. A small ICC occurs when within-group variation is large compared with between-group variability, indicating that some unknown variable has introduced non-random effects in the different groups. A linear mixed-effect model was used to calculate variance components and $95 \%$ confidence intervals (95\% CI) for eyes, OCT devices, 
and scan types. Commercial software (Stata, ver. 9.2; StataCorp, College Station, TX) was used for analysis.

\section{Results}

The mean age of the study subjects was $78 \pm 6$ years, with a range of 42-88 years. Eighteen patients were female. Good quality OCT scans could be performed in all 30 eyes with Stratus ${ }^{\text {TM }}$ OCT (FMS and CHS) and Spectralis ${ }^{\mathrm{TM}}$ OCT (VS and RLS). Table 1 shows variance components with $95 \%$ confidence intervals for eyes, OCT device, scan type, and the corresponding ICCs for the agreement of OCT image grading. In Stratus ${ }^{\mathrm{TM}}$ OCT the highest agreement was found for SRF (ICC Stratus $_{\text {TM: }}$ 0.79). In Spectralis ${ }^{\mathrm{TM}}$ OCT the highest ICC was found for identification of IRC $\left(\mathrm{ICC}_{\text {Spectralis }}{ }^{\mathrm{TM}}\right.$ : 0.93). Lowest agreement was found for SHM with an $\mathrm{ICC}_{\mathrm{Stratus}^{\mathrm{TM}}}$ of 0.65 , and an $\mathrm{ICC}_{\text {Spectralis }^{\mathrm{TM}}}$ of 0.52 . Spectralis ${ }^{\mathrm{TM}}$ OCT showed marked superior inter-observer agreement for IRC and ERM compared to Stratus ${ }^{\mathrm{TM}}$ OCT.

\section{Discussion}

In our study, Spectralis ${ }^{\mathrm{TM}}$ OCT showed superior interobserver agreement for grading IRC and ERM. This suggests that increased image resolution might be beneficial for grading pathologies that are located in the vitreo-retinal interface or in the neurosensory retina. In addition, the increased retinal coverage increased the chance of finding pathologies. This might also explain the better agreement. The used SD-OCT device was operated with 25 line scans for each raster scan although it is capable of performing more line scans if necessary. Other SD-OCT models use raster scans with up to 128 line-scans which increases retinal coverage even more. Interestingly, the improved image resolution and scan coverage of SD-OCT did not significantly improve inter-observer OCT image grading agreement for most other pathologies tested.

Lowest inter-observer agreement was found for SHM. It seems to be difficult to distinguish SHM from other pigment epithelial changes, intraretinal blood, or increased light penetration artifacts due to pigment epithelium atrophy. These findings are in agreement with previous studies of Zhang et al. [26] who tested OCT reader agreement in neovascular AMD by comparing 3 observers, who were certified by an OCT reading center. All observers used a standardized grading protocol. Two different scan protocols (FMS and $7 \mathrm{~mm}$ line scan) were compared and all scans were performed with the Stratus ${ }^{\mathrm{TM}}$ OCT. Inter-observer agreement was found to be high for 7 of 8 pathologies tested (IRC, SRF, ERM, PED, macular edema, vitreomacular interface changes, choroidal neovascularisations) ranging from 79 to $98 \%$. Observer agreement for pigment epithelium atrophy was significantly lower and ranged from 43 to $50 \%$. No significant differences were found between the two tested scan types.

Recently, Sayanagi et al. [37] compared 4 different SD-OCT models versus TD-OCT for the management of neovascular AMD. In their study, inter-observer reproducibility for OCT image grading was not tested, but they found all 4 SD-OCT models to be superior in detecting SRF, IRC, intraretinal fluid and sub-RPE fluid compared to TD-OCT. In contrast, our results

Table 1 Inter-observer agreement of OCT image grading for different pathologies

\begin{tabular}{lllllllll}
\hline & Var. eye & $95 \%$ CI & Var. OCT type & $95 \%$ CI & Var. scantype & $95 \%$ CI & ICC Stratus $^{\text {TM }}$ & ICC Spectralis $^{\mathrm{TM}}$ \\
\hline IRC & 9.68 & $4.1-22$ & 1.93 & $0.46-7.98$ & 0.98 & $0.15-6.39$ & 0.61 & 0.93 \\
SRF & 7.07 & $2.64-18.9$ & 3.91 & $1.38-11.13$ & $5.46 \mathrm{e}-14$ & 0 & 0.79 & 0.73 \\
PED & 5.2 & $2.21-12.26$ & 0.91 & $0.2-4.19$ & $2.57 \mathrm{e}-14$ & 0 & 0.66 & 0.66 \\
ERM & 6.24 & $1.98-19.68$ & 2.31 & $0.46-11.68$ & 0.78 & $0.05-13.35$ & 0.56 & 0.84 \\
SHM & 3.77 & $1.87-7.61$ & 0.27 & $0.02-4.41$ & $3.80 \mathrm{e}-22$ & 0 & 0.65 & 0.52 \\
\hline
\end{tabular}

Intraclass correlation coefficient (ICC) values are presented for Stratus ${ }^{\mathrm{TM}}$ OCT, and Spectralis ${ }^{\mathrm{TM}}$ OCT inter-observer agreement The linear mixed model was used to calculate ICCs. ICC Stratus ${ }^{\mathrm{TM}}=$ Inter-observer agreement of Stratus ${ }^{\mathrm{TM}}$ OCT image grading in regard of given pathology

ICC Spectralis $^{\mathrm{TM}}=$ Inter-observer agreement of Spectralis ${ }^{\mathrm{TM}}$ OCT image grading in regard of given pathology

Var. variance; $C I$ confidence interval; IRC intra-retinal cyst; SRF sub-retinal fluid; PED pigment epithelium detachment; ERM epiretinal membrane; $S H M$ subretinal hyper-reflective material 
showed no differences between OCT types in grading PED and SRF. One can hypothesize that image resolution of TD-OCT seems to be sufficient to identify all PED and SRF if present in line scans.

Although the previously published data indicates a relatively good inter-observer agreement in OCT reading centers, one has to be cautious in assuming the same inter-observer agreement in daily clinical routine [26]. Usually, treating physicians are not trained by an OCT reading center and personal clinical experience is applied when deciding on re-treatment rather than a standardized OCT grading protocol. In larger clinics, the same patient is often treated by various ophthalmologists. Therefore, inter-observer variability in OCT image grading might even lead to changing treatment protocols in patients with neovascular AMD. In this study, observers were experienced OCT user but not specifically trained by an OCT reading center. This might explain the lower interobserver agreement compared to previously published data [26].

Previously, automated quantitative subanalysis of morphologic pathologies such as PEDs and SRF has been introduced for computer assisted image grading $[24,38]$. Such software systems are however not common and are mostly used for quantitative analysis. Our data indicates that most pathologies can be graded with good inter-observer agreement regardless of the used OCT device without automated sub-analysis tools. However, agreement was poor for grading SHM in both OCT devices. To our knowledge, no automated sub-analysis tool is available for identification and quantification of SHM. Since subretinal hemorrhages, choroidal neovascularisations and subretinal scar tissue appears very similar in OCT, further diagnostics will be needed to differentiate these conditions from each other.

In conclusion, our study showed relatively good inter-observer agreement for most tested pathologies for both OCT devices, except for SHM. Spectralis ${ }^{\mathrm{TM}}$ OCT showed superior inter-observer agreement for IRC and ERM. This indicates that increased image resolution of SD-OCT might show structural abnormalities located in the vitreo-retinal interface or in the neurosensory retina more accurately, which facilitates image grading for these morphologic changes.

Ethical standard The study was performed with informed consent and followed all the guidelines for experimental investigations required by the Ethics Committee of the University of Zurich which approved this study.

\section{References}

1. Huang D, Swanson EA, Lin CP, Schuman JS, Stinson WG, Chang W, Hee MR, Flotte T, Gregory K, Puliafito CA et al (1991) Optical coherence tomography. Science 254(5035): $1178-1181$

2. Hee MR, Izatt JA, Swanson EA, Huang D, Schuman JS, Lin CP, Puliafito CA, Fujimoto JG (1995) Optical coherence tomography of the human retina. Arch Ophthalmol 113(3):325-332

3. Puliafito CA, Hee MR, Lin CP, ReichelE, Schuman JS, Duker JS, Izatt JA, Swanson EA, Fujimoto JG (1995) Imaging of macular diseases with optical coherence tomography. Ophthalmology 102(2):217-229

4. Hee MR, Baumal CR, Puliafito CA, Duker JS, Reichel E, Wilkins JR, Coker JG, Schuman JS, Swanson EA, Fujimoto JG (1996) Optical coherence tomography of age-related macular degeneration and choroidal neovascularization. Ophthalmology 103(8):1260-1270

5. Spraul CW, Lang GE, Lang GK (1998) Value of optical coherence tomography in diagnosis of age-related macular degeneration. Correlation of fluorescein angiography and OCT findings. Klin Monbl Augenheilkd 212(3):141-148

6. Giovannini A, Amato GP, Mariotti C, Scassellati-Sforzolini B (1999) OCT imaging of choroidal neovascularization and its role in the determination of patients' eligibility for surgery. Br J Ophthalmol 83(4):438-442

7. Van Kerckhoven W, Lafaut B, Follens I, De Laey JJ (2001) Features of age-related macular degeneration on optical coherence tomography. Bull Soc Belge Ophtalmol 281:75-84

8. Eter N, Bindewald A, Roth F, Holz FG (2004) OCT in agerelated macular degeneration. Findings, usage in clinical routine, and assessment of treatment outcome. Ophthalmologe 101(8):794-803

9. Ting TD, Oh M, Cox TA, Meyer CH, Toth CA (2002) Decreased visual acuity associated with cystoid macular edema in neovascular age-related macular degeneration. Arch Ophthalmol 120(6):731-737

10. Costa RA, Farah ME, Cardillo JA, Calucci D, Williams GA (2003) Immediate indocyanine green angiography and optical coherence tomography evaluation after photodynamic therapy for subfoveal choroidal neovascularization. Retina 23(2):159-165

11. Rogers AH, Martidis A, Greenberg PB, Puliafito CA (2002) Optical coherence tomography findings following photodynamic therapy of choroidal neovascularization. Am J Ophthalmol 134(4):566-576

12. Michels S, Rosenfeld PJ, Puliafito CA, Marcus EN, Venkatraman AS (2005) Systemic bevacizumab (Avastin) therapy for neovascular age-related macular degeneration twelve-week results of an uncontrolled open-label clinical study. Ophthalmology 112(6):1035-1047

13. Talks J, Koshy Z, Chatzinikolas K (2007) Use of optical coherence tomography, fluorescein angiography and indocyanine green angiography in a screening clinic for wet agerelated macular degeneration. $\mathrm{Br} \mathrm{J}$ Ophthalmol 91(5): 600-601 
14. Coscas F, Coscas G, Souied E, Tick S, Soubrane G (2007) Optical coherence tomography identification of occult choroidal neovascularization in age-related macular degeneration. Am J Ophthalmol 144(4):592-599

15. Menke MN, Feke GT (2005) Assessment of the effects of morphological changes related to age-related macular degeneration on optical coherence tomography retinal thickness measurements. Ophthalmic Surg Lasers Imaging 36(4): 310-314

16. Fung AE, Lalwani GA, Rosenfeld PJ, Dubovy SR, Michels S, Feuer WJ, Puliafito CA, Davis JL, Flynn HW Jr, Esquiabro M (2007) An optical coherence tomography-guided, variable dosing regimen with intravitreal ranibizumab (Lucentis) for neovascular age-related macular degeneration. Am J Ophthalmol 143(4):566-583

17. Bashshur ZF, Bazarbachi A, Schakal A, Haddad ZA, El Haibi CP, Noureddin BN (2006) Intravitreal bevacizumab for the management of choroidal neovascularization in agerelated macular degeneration. Am J Ophthalmol 142(1):1-9

18. Bashshur ZF, Haddad ZA, Schakal A, Jaafar RF, Saab M, Noureddin BN (2008) Intravitreal bevacizumab for treatment of neovascular age-related macular degeneration: a one-year prospective study. Am J Ophthalmol 145(2): 249-256

19. Bashshur ZF, Schakal A, Hamam RN, El Haibi CP, Jaafar RF, Noureddin BN (2007) Intravitreal bevacizumab vs verteporfin photodynamic therapy for neovascular agerelated macular degeneration. Arch Ophthalmol 125(10): 1357-1361

20. Menke MN, Dabov S, Knecht P, Sturm V (2008) Reproducibility of retinal thickness measurements in healthy subjects using spectralis optical coherence tomography. Am J Ophthalmol 147(3):467-472

21. Patel PJ, Chen FK, Ikeji F, Xing W, Bunce C, Da Cruz L, Tufail A (2008) Repeatability of stratus optical coherence tomography measures in neovascular age-related macular degeneration. Invest Ophthalmol Vis Sci 49(3):1084-1088

22. Tangelder GJ, Van der Heijde RG, Polak BC, Ringens PJ (2008) Precision and reliability of retinal thickness measurements in foveal and extrafoveal areas of healthy and diabetic eyes. Invest Ophthalmol Vis Sci 49(6):2627-2634

23. Legarreta JE, Gregori G, Punjabi OS, Knighton RW, Lalwani GA, Puliafito CA (2008) Macular thickness measurements in normal eyes using spectral domain optical coherence tomography. Ophthalmic Surg Lasers Imaging 39(4 Suppl):S43-49

24. Joeres S, Tsong JW, Updike PG, Collins AT, Dustin L, Walsh AC, Romano PW, Sadda SR (2007) Reproducibility of quantitative optical coherence tomography subanalysis in neovascular age-related macular degeneration. Invest Ophthalmol Vis Sci 48(9):4300-4307

25. Krzystolik MG, Strauber SF, Aiello LP, Beck RW, Berger BB, Bressler NM, Browning DJ, Chambers RB, Danis RP, Davis MD, Glassman AR, Gonzalez VH, Greenberg PB, Gross JG, Kim JE, Kollman C (2007) Reproducibility of macular thickness and volume using Zeiss optical coherence tomography in patients with diabetic macular edema. Ophthalmology 114(8):1520-1525
26. Zhang N, Hoffmeyer GC, Young ES, Burns RE, Winter KP, Stinnett SS, Toth CA, Jaffe GJ (2007) Optical coherence tomography reader agreement in neovascular age-related macular degeneration. Am J Ophthalmol 144(1):37-44

27. Tatlipinar S, Shah SM, Campochiaro PA, Nguyen QD (2007) Intraobserver repeatability of automated versus adjusted optical coherence tomography measurements in patients with neovascular age-related macular degeneration. Ophthalmologica 221(4):227-232

28. Choma MASM, Yang C, Izatt JA (2003) Sensitivity advantage of swept source and Fourier Domain optical coherence tomography. Opt Express 11:2183-2189

29. Wojtkowski M, Srinivasan V, Fujimoto JG, Ko T, Schuman JS, Kowalczyk A, Duker JS (2005) Three-dimensional retinal imaging with high-speed ultrahigh-resolution optical coherence tomography. Ophthalmology 112(10):1734-1746

30. Wojtkowski M, Srinivasan V, Fujimoto JG et al (2004) Ultrahigh-resolution, high-speed, Fourier domain optical coherence tomography and methods for dispersion compensation. Opt Express 12:2404-2422

31. Wojtkowski M, Srinivasan V, Ko T et al (2005) High speed, ultrahigh resolution retinal imaging using spectral/Fourier domain OCT. Conf Lasers Electro Optics 3:2058-2060

32. Srinivasan VJ, Wojtkowski M, Witkin AJ, Duker JS, Ko TH, Carvalho M, Schuman JS, Kowalczyk A, Fujimoto JG (2006) High-definition and 3-dimensional imaging of macular pathologies with high-speed ultrahigh-resolution optical coherence tomography. Ophthalmology 113(11):2054.e12054.e14. doi:10.1016/j.ophtha.2006.05.046

33. Alam S, Zawadzki RJ, Choi S, Gerth C, Park SS, Morse L, Werner JS (2006) Clinical application of rapid serial Fourier-domain optical coherence tomography for macular imaging. Ophthalmology 113(8):1425-1431

34. Schmidt-Erfurth U, Leitgeb RA, Michels S, Povazay B, Sacu S, Hermann B, Ahlers C, Sattmann H, Scholda C, Fercher AF, Drexler W (2005) Three-dimensional ultrahigh-resolution optical coherence tomography of macular diseases. Invest Ophthalmol Vis Sci 46(9):3393-3402

35. Ahlers C, Geitzenauer W, Simader C, Stock G, Golbaz I, Polak K, Georgopoulos M, Schmidt-Erfurth U (2008) New perspectives in diagnostic. High-resolution optical coherence tomography for age-related macular degeneration. Ophthalmologe 105(3):248-254

36. Menke MN, Dabov S, Sturm V (2008) Features of agerelated macular degeneration assessed with three-dimensional Fourier-domain optical coherence tomography. Br J Ophthalmol 92(11):1492-1497

37. Sayanagi K, Sharma S, Yamamoto T, Kaiser PK (2009) Comparison of spectral-domain versus time-domain optical coherence tomography in management of age-related macular degeneration with ranibizumab. Ophthalmology 116(5):947-955. doi:10.1016/j.ophtha.2008.11.002

38. Keane PA, Liakopoulos S, Ongchin SC, Heussen FM, Msutta S, Chang KT, Walsh AC, Sadda SR (2008) Quantitative subanalysis of optical coherence tomography after treatment with ranibizumab for neovascular age-related macular degeneration. Invest Ophthalmol Vis Sci 49(7): $3115-3120$ 